\title{
Assessing the invasion potential of non-native branchiobdellidans: experimental studies of survival, reproduction and competition
}

\author{
Joanna James ${ }^{\text {a }}$ Kate E. Davidson, Rhiannon Hunt and Jo Cable* \\ School of Biosciences, Cardiff University, Cardiff CF10 3AX, UK
}

\begin{abstract}
The impact of invasive species on the recipient ecosystem can be strongly influenced by the presence of associated symbionts. It is therefore important to evaluate the likelihood of co-introduced symbiont establishment, and this requires an understanding of their life history traits. Here, we investigate survival, reproduction and competition in two non-native branchiobdellidan ectosymbionts (Xironogiton victoriensis and Cambarincola aff. okadai) on invasive signal crayfish (Pacifastacus leniusculus). In vivo, X. victoriensis established viable infrapopulations within 10 weeks, whereas $C$. aff. okada $i$ went extinct within 2 weeks. Both $X$. victoriensis and $C$. aff. okadai deposited cocoons in vivo that hatched in 10-27 and 10-11 days, respectively. In vitro, $X$. victoriensis and $C$. aff. okadai survived for over 13 and 15 weeks respectively, although both were negatively affected by increased temperature and nitrate, and were absent from kick samples taken in the field. Only $C$. aff. okadai deposited cocoons in vitro, and this larger species readily predated on $X$. victoriensis but not vice versa. Both branchiobdellidans possess traits associated with colonisation success, including a relatively fast reproductive rate and extended off-host survival. Given its survival in vivo and known detrimental effect on signal crayfish $X$. victoriensis is perhaps more likely to influence host invasion dynamics, although its persistence may be affected by the presence of co-occurring symbionts.
\end{abstract}

Keywords: invasive non-native species / invasive parasites / climate change / signal crayfish / Xironogiton victoriensis

Résumé - Évaluation du potentiel invasif de Branchiobdellidés non indigènes: études expérimentales de survie, de reproduction et de compétition. L'impact des espèces envahissantes sur l'écosystème récepteur peut être fortement influencé par la présence de symbiotes associés. Il est donc important d'évaluer la probabilité d'un établissement de symbiotes co-introduits, ce qui nécessite une compréhension de leurs traits d'histoire de vie. Ici, nous étudions la survie, la reproduction et la compétition de deux ectosymbiontes branchiobdellidés non indigènes (Xironogiton victoriensis et Cambarincola aff. okadai) sur l'écrevisse signal invasive (Pacifastacus leniusculus). In vivo, X. victoriensis a établi des infrapopulations viables en 10 semaines, alors que $C$. aff. okadai s'est éteint dans les 2 semaines. $X$. victoriensis et $C$. aff. okadai ont déposé des cocons in vivo qui ont éclos en 10-27 et 10-11 jours respectivement. In vitro, X. victoriensis et C. aff. okadai ont survécu pendant plus de 13 et 15 semaines respectivement, bien que les deux aient été affectés négativement par l'augmentation de la température et du nitrate, et étaient absents des prélèvements prélevés sur le terrain. Seul $C$. aff. okadai a déposé des cocons in vitro, et cette espèce plus grande était prédateur sur $X$. victoriensis mais pas l'inverse. Les deux branchiobdellidés possèdent des traits associés à la réussite de la colonisation, y compris un taux de reproduction relativement rapide et une survie prolongée hors de l'hôte. Compte tenu de sa survie in vivo et de son effet nuisible connu sur les écrevisses signal, $X$. victoriensis est peutêtre plus susceptible d'influencer la dynamique d'invasion de l'hôte, bien que sa persistance soit affectée par la présence de symbiotes co-présents.

Mots-clés : espèces envahissantes non indigènes / parasites envahissants / changements climatiques / écrevisse signal / Xironogiton victoriensis

\footnotetext{
${ }^{a}$ Current address: National Fisheries Services, The Environment Agency, Bromholme Lane, Brampton PE28 4NE, UK.

${ }^{*}$ Corresponding author: cablej@cardiff.ac.uk
} 


\section{Introduction}

Symbionts can be key in determining the outcome of biological invasions (Prenter et al., 2004; Sargent et al., 2014), one of the main causes of biodiversity loss (Gurevitch and Padilla, 2004; Didham et al., 2005). The majority of introduced symbionts, however, fail to establish (MacLeod et al., 2010), and predicting this is difficult as there is no single life-history strategy indicative of a successful invasion (Sol et al., 2012; Lockwood et al., 2013). Typically, invaders have a high dispersal ability and reproductive capacity, often involving hermaphroditism and/or asexual reproduction (MacArthur and Wilson, 1967). Having a broad environmental tolerance is also predicted to increase the likelihood of successful colonisation. For symbionts, host dispersal, host specificity and life cycle complexity are also important predictors of invasive status (Kennedy, 1994), with those infecting highly mobile hosts and having a simple direct life cycle being the most likely to successfully colonise.

Here, we assess the invasion potential of branchiobdellidan (Annelida: Clitellata) ectosymbionts, commonly found on crayfish throughout the Holarctic (Gelder, 1999). Previous studies indicate that the crayfish-branchiobdellidan association can vary from mutualistic to parasitic (reviewed by Skelton et al., 2013). Therefore, these symbionts could influence the invasion success of non-native crayfish either beneficially or detrimentally. Relatively few reports exist of non-native branchiobdellidans in Europe despite the large number of crayfish introductions in recent decades (Souty-Grosset et al., 2006; Holdich et al., 2014; James et al., 2014; Kouba et al., 2014). This may be due to a lack of monitoring or because branchiobdellidans are poor invaders. Branchiobdellidans are sexually reproducing hermaphrodites, which deposit fertilised cocoons directly onto the host's exoskeleton (Govedich et al., 2009). As monoxenous species, they have no requirement for an intermediate host (Taraschewski, 2006) and are directly transmitted between crayfish (Govedich et al., 2009). Furthermore, branchiobdellidans appear to be generalists with respect to host species (Skelton et al., 2013).

Branchiobdellidan survival, reproduction and environmental requirements are relatively poorly understood, perhaps with the exception of the genus Cambarincola. Existing in vitro studies indicate that survival can range from 46 days to over two months (Penn, 1959; Niwa et al., 2014; Creed et al., 2015), although this is likely to vary by species and limited data is available to quantify this. In vivo, branchiobdellidans of the genus Cambarincola produce cocoons that can hatch in 10-12 days, although this can take over 23 days (Creed et al., 2015). These are short generation times compared to some other hermaphroditic freshwater annelids, including most predatory leeches (Hirudinida) that tend to reproduce annually or biannually, display semelparity and take up to 19 months to mature (Govedich et al., 2009). Also, for some freshwater Oligochaeta (Lumbriculida) cocoons can take one to two months to hatch, and full maturity is not reached for around two years (Cook, 1969). In terms of environmental tolerance, again there is a paucity of information but some branchiobdellidans can survive in temperatures up to $33^{\circ} \mathrm{C}$ (DeWitt et al., 2013). Thus, branchiobdellidans possess some traits associated with successful colonists; although, this is likely to be species-dependant and information is sparse.
Two non-native species of branchiobdellidans, Cambarincola aff. okadai and Xironogiton victoriensis, were recently found for the first time on invasive signal crayfish (Pacifastacus leniusculus) in the UK (James et al., 2015a). Signal crayfish are widespread across the UK (James et al., 2014), and have altered the structure and function of recipient ecosystems throughout their non-native range (James et al., 2015c). Under laboratory conditions, $X$. victoriensis reduces aggression and foraging efficiency of signal crayfish (James et al., 2015b), which may alter host invasion dynamics in the field. Given the high frequency of co-infection between $C$. aff. okadai and $X$. victoriensis (see James et al., 2015a), intraguild competition and predation may also predict the likelihood of either species persisting.

In a series of in vivo and in vitro experiments we assessed the potential invasion ability of $C$. aff. okadai and $X$. victoriensis. In vivo we monitored branchiobdellidan infrapopulation survival and individual worm reproduction on signal crayfish hosts. In vitro, we investigated branchiobdellidan survival and reproduction under altered temperature and nitrate conditions, and assessed competition between these co-habiting symbionts.

\section{Methods}

\subsection{Collection and maintenance of animals}

Crayfish, collected by trapping and manual searching in March-October of 2012-2014, were transported to the aquarium facility at Cardiff University. Signal crayfish ( $P$. leniusculus) naïve to branchiobdellidan worms were collected from three sites in Powys, mid-Wales: Dderw Farm Pond, Llyswen (SO138375); Rhydlydan ponds, Painscastle (SO168457); and the River Bachowey, Painscastle (SO166457). All recipient host crayfish were sexed, weighed (blotted wet mass), measured (total carapace length: tip of rostrum to posterior margin of the carapace) and visually inspected for signs of disease. Any crayfish displaying signs of ill health, in the premoult stage, or missing chelae were excluded from the study. Given their tendency to moult frequently small crayfish (carapace length $<28 \mathrm{~mm}$ ) were also omitted from experiments. Signal crayfish harbouring branchiobdellidans $(X$. victoriensis and $C$. aff. okadai identified according to James et al. (2015a) were collected from the River Gavenny (SO308164), South Wales.

All crayfish were maintained under a $16 \mathrm{~h}: 8 \mathrm{~h}$ light/dark regime in aerated, filtered $180 \mathrm{~L}$ tanks filled with dechlorinated water $\left(15 \pm 1^{\circ} \mathrm{C}\right)$, gravel substrates and refugia. The animals were fed every 24 or $48 \mathrm{~h}$ on Tetra Crusta flakes and weekly $50 \%$ water changes were performed in both stock and experimental tanks. Branchiobdellidan-naïve crayfish were maintained separately from infested crayfish, and no equipment was shared between the tanks, to ensure naïve crayfish had no exposure to branchiobdellidans prior to their use in experiments. Crayfish were given a minimum of 7 days to acclimatise to laboratory conditions before being used for experiments.

Worms were carefully dislodged from host crayfish using the edge of blunt forceps and placed in a glass dish of distilled water. Removal from the host did not cause any visible damage or behavioural change to the worms, and they readily re- 
attached to the surface of the dish. Worms were examined under a dissecting microscope $(\times 30)$ with fibre optic illumination and only apparently healthy, full-sized ( $>3.0 \mathrm{~mm}$ for $X$. victoriensis, $>8.0 \mathrm{~mm}$ for $C$. aff. okadai), specimens were used in experiments. $C$. aff. okadai is less abundant than $X$. victoriensis in the Welsh population (James et al., 2015a) and more difficult to maintain in the lab, and therefore could not be tested under all experimental conditions.

To determine whether branchiobdellidans living off the host could be found in the field, benthic invertebrate samples from the River Gavenny site $(n=6)$ were collected in September 2012 by kick-sampling for 1 min using a standard net $(0.25 \mathrm{~m} \times 0.25 \mathrm{~m}$ with a $0.5 \mathrm{~mm}$ mesh $)$ and stored in $70 \%$ ethanol. Samples were subsequently examined under a dissecting microscope for the presence of any branchiobdellidans.

\subsection{In vivo survival and reproduction}

To investigate the persistence of worm populations on the host, naïve signal crayfish $(n=40)$ were experimentally infected with $X$. victoriensis worms. Infection intensities represented those naturally present in the field, based on crayfish size category (carapace length, $\mathrm{mm}$ ): 28-31; 32-35; $36-39 ; 40-43 ; 44-48$ infected with $21,28,65,101$ and 154 worms respectively (James et al., 2015a). Host crayfish were maintained individually in aerated $15 \mathrm{~L}$ plastic tanks with a plastic refuge. Crayfish were screened and the number of worms counted each week for 10 weeks. At each screening, any lost worms were replaced with new ones to maintain worm numbers at natural levels and simulate branchiobdellidan transmission. If a crayfish moulted, this was recorded, and the moult was left in the tank for at least $24 \mathrm{~h}$ to allow worms to transfer back onto the crayfish.

To assess the time for cocoon deposition and hatching, branchiobdellidan-naïve signal crayfish were infected with a single adult worm $(X$. victoriensis $n=18, C$. aff. okadai $n=20$ ). Host crayfish were maintained individually in aerated $10 \mathrm{~L}$ plastic tanks with a refuge. Crayfish were inspected every $48 \mathrm{~h}$ for the presence of adult worms and cocoons. If a crayfish moulted, the exoskeleton was left in the tank for $24 \mathrm{~h}$ to allow the worm to move back onto the crayfish. Following cocoon deposition, the adult worm was removed from the host and the cocoon was examined every $48 \mathrm{~h}$ in vivo under a dissecting microscope to detect emergence of the juvenile. If the host moulted following cocoon deposition, the crayfish was removed from the tank so that cocoon development could be monitored on the exuviae until detection was no longer possible due to disintegration of the exuviae (ca. 2 weeks). The experiment was terminated when all cocoons had either hatched or there had been no change in the condition of the worm or cocoon for at least 30 days. We considered extending this study to native white-clawed crayfish (Austropotamobius pallipes) but it was not possible to gain ethical clearance to assess whether these endangered hosts were also susceptible to $X$. victoriensis and, or $C$. aff. okadai.

To assess the interval between cocoon deposition, the above procedure was repeated (using $X$. victoriensis only, $n=16$ ) but adult worms were left on the host following deposition of the initial cocoon. Crayfish were examined every $48 \mathrm{~h}$ and the presence and location of worms and cocoons were recorded. Cocoons were examined under a dissecting microscope to determine when the juvenile worm had emerged. The experiment was terminated after 30 days.

\subsection{In vitro survival, reproduction, cannibalism and intraguild predation}

To assess survival and reproduction in vitro, individual worms were removed from their host and transferred to petri dishes (dia. $50 \mathrm{~mm}$ ) containing $10 \mathrm{ml}$ water. Petri dishes were kept under two or four different conditions for $C$. aff. okadai and $X$. victoriensis, respectively ( $n=20$ worms per treatment). Survival of both species was investigated at $15 \pm 1{ }^{\circ} \mathrm{C}$ and $20 \pm 0.5^{\circ} \mathrm{C}$. Survival of $X$. victoriensis was also assessed in low $(<5 \mathrm{ppm})$ and high $(100 \mathrm{ppm})$ nitrate water, but $C$. aff. okadai worms were only available for exposure to low nitrate water. Nitrate solutions were prepared by dissolving potassium nitrate ( $\geq 99.0 \%$ purity $\mathrm{K}\left(\mathrm{NO}_{3}\right)$, Sigma-Aldrich, USA) into dechlorinated tap water. Nitrate levels were tested with an API ${ }^{\circledR}$ Freshwater Master Test Kit. Worms were assessed weekly under a dissecting microscope to check for the deposition of cocoons and monitor condition until death occurred. When cocoons were detected they were transferred to a new petri dish under identical conditions and screened every $48 \mathrm{~h}$ using a dissecting microscope to assess hatching time and juvenile survival.

To investigate cannibalism and intraguild predation between co-habiting branchiobdellidans, five treatments were tested: inter-specific $C$. aff. okadai and $X$. victoriensis pairs, intra-specific $C$. aff. okadai or $X$. victoriensis pairs and two controls of a single $C$. aff. okadai or $X$. victoriensis $(n=25$ for each treatment, except $C$. aff. okadai intra-specific pairs where $n=18$ due to a lack of available specimens). These experiments were run in vitro to allow us to investigate cannibalism/ intraguild predation without the confounding effects of host grooming. $X$. victoriensis and $C$. aff. okadai were placed into petri dishes filled with water from crayfish stock tanks to prevent starvation (general diet of branchiobdellidans includes diatoms, invertebrates and unicellular algae alongside crayfish exuviae; Govedich et al., 2009) and the survival of each branchiobdellidan monitored over six weeks. To estimate the size difference between each pair (without fixing), branchiobdellidans were coaxed to naturally stretch out by disturbing the water. Video was recorded using a smart phone camera (Samsung Galaxy S4 Mini) and a still image taken when the branchiobdellidan was fully extended. Branchiobdellidan length was measured from these images using ImageJ (Rasband, 2017). Petri dishes were checked every day to record death or consumption of a branchiobdellidan.

\subsection{Statistical analysis}

All general linear models (GLMs) and generalised linear models were minimised by stepwise deletion of insignificant terms using analysis of variance. For all models, visual examination of data plots and Shapiro-Wilk tests were used to check standardised residuals for normal distribution and homogeneity of variance (Thomas et al., 2013). In all tests, the level of significance was taken as $P<0.05$. All statistical analyses were conducted in the R statistical package v2.15.1 


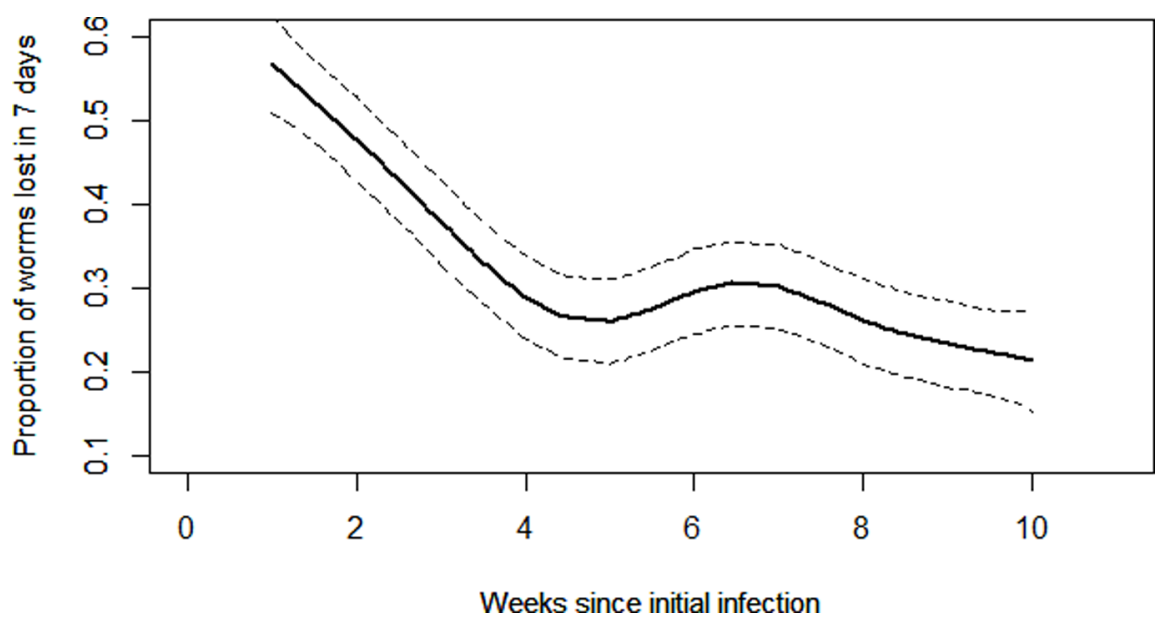

Fig. 1. Predicted proportion of Xironogiton victoriensis worms lost from initially naïve signal crayfish host each week, as a function of time since initial experimental infection. Additional worms were experimentally added to the crayfish each week to simulate transmission from host to host. Dashed lines represent $95 \%$ confidence intervals.

(R Development Core Team, 2012), with ASReml-R (version 3.0 package) used to conduct the generalised linear mixed model (GLMM) within the $\mathrm{R}$ interface.

A GLMM with a Gaussian error distribution and identity link was used to determine whether host size (carapace length), sex, moulting or time in the experiment had an effect on the weekly proportion of worms lost from crayfish artificially infected with natural branchiobdellidan intensities (Model 1). Interactions between sex and size and between sex and time were also included as fixed effects in the starting model. To detect any non-linear effects of time on worm loss, a spline was fitted to this variable and it was included as a random variable in Model 1. Assessment of the log-likelihood ratio was used to determine whether time was a significant random effect. Crayfish identification number was also included as a random factor in Model 1, to control for repeated measures. Following assessment of the random model, the fixed model was refined by stepwise deletions using the Wald statistic. For crayfish experimentally infected with individual worms, a Pearson's chi-squared test was used to assess whether the number of hosts that lost their branchiobdellidans differed between $X$. victoriensis and $C$. aff. okadai.

In vitro branchiobdellidan survival was analysed using two separate GLMs. Model 2a explored the effect of species, temperature and the interaction between these variables on survival, whilst Model $2 \mathrm{~b}$ investigated the effect of temperature, nitrate and their interaction on $X$. victoriensis survival.

Intraguild predation and cannibalism among $X$. victoriensis and $C$. aff. okadai were investigated using a Generalised Linear Model with a binomial error distribution and logit link function. Treatment and size difference between branchiobdellidan pairs $(\mathrm{mm})$ were controlled for as independent variables. A second order interaction between treatment and size difference was included as a fixed effect in the starting model, as there was a larger size difference among the interspecific pairs than the intraspecific pairs. Significant differences in survival between treatments were examined with a Tukey multiple comparisons of means using the package "multcompView" (Graves et al., 2015).

\section{Results}

During the course of all experiments, it was evident that $X$. victoriensis tolerated laboratory conditions better than $C$. aff. okadai, surviving on crayfish hosts for $>5$ months compared to $<2$ weeks for $C$. aff. okadai cultures $\left(15 \pm 1^{\circ} \mathrm{C}\right)$. Despite this, both species reproduced successfully in vivo. In vitro survival in water did not differ between the two species, but only $C$. aff. okadai deposited cocoons, which hatched successfully. $C$. aff. okadai readily predated on $X$. victoriensis and cannibalism was observed in both species in vitro. No worms of either species were found in the invertebrate samples from the River Gavenny where infected crayfish were collected. This finding is supported by previous extensive sampling of Welsh rivers over the last 35 years, in which no branchiobdellians were recovered from conventional benthic samples (Ormerod, personal communication).

\subsection{In vivo survival and reproduction}

Over 10 weeks, $X$. victoriensis infrapopulations on experimentally infected signal crayfish, which were reinfected weekly to maintain natural mean infection intensities, decreased by an average of $33.1 \%$ each week. There was, however, a significant, non-linear relationship between time and the proportion of worms lost $\left(F_{1,334}=121, P<0.0001\right)$, with the high initial rate of loss $($ mean $=56.5 \%$ in week 1$)$ reducing over time $($ mean $=21.5 \%$ in week 10 ; Fig. 1$)$. The weekly percentage decrease in worm numbers was not affected by crayfish sex, size, nor host moulting in the preceding week (all $P>0.05$ ).

For $32.4 \%(11 / 34)$ of crayfish experimentally infected with a single $X$. victoriensis worm, we were not able to detect the branchiobdellidan $48 \mathrm{~h}$ post infection. Of the 23 remaining worms, $95.7 \%$ deposited cocoons on their hosts within the 30 day experiment. The mean time to lay the first cocoon was five days (range 2-28) and the cocoons hatched after 10-27 days (mean 18.8) at $15 \pm 1{ }^{\circ} \mathrm{C}$. Six crayfish moulted before the 
a)

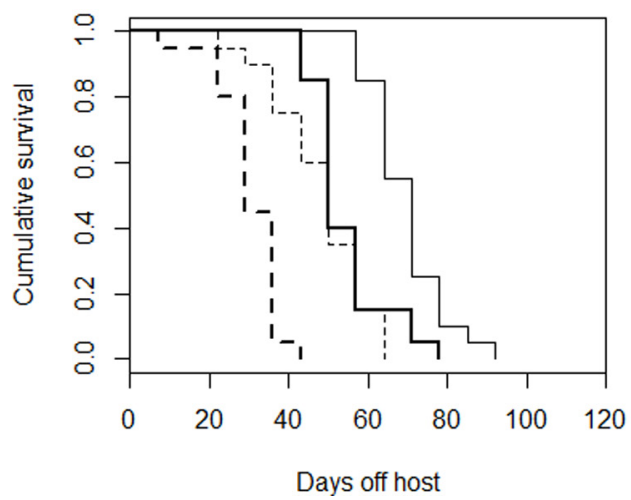

b)

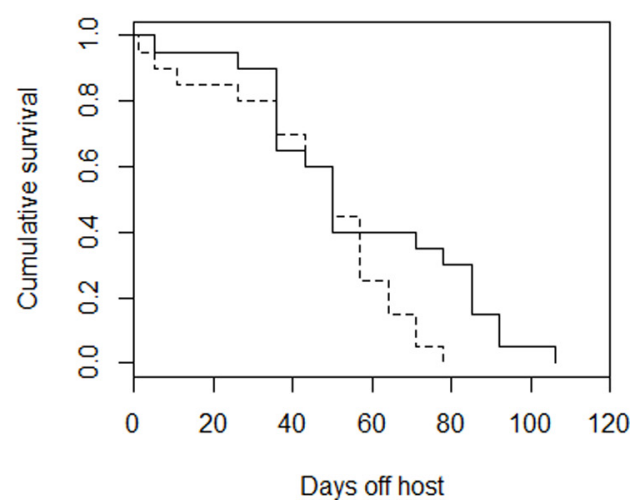

Fig. 2. Cumulative in vitro survival of branchiobdellidans at $15^{\circ} \mathrm{C}$ (solid lines) or $20^{\circ} \mathrm{C}$ (dashed lines) in low nitrate (light lines) or high nitrate (bold lines) water of (a) Xironogiton victoriensis and (b) Cambarincola aff. okadai.

Table 1. Mean (range) survival (days) of Xironogiton victoriensis and Cambarincola aff. okadai in vitro under various temperature and nitrate regimes $(n=20$ per treatment).

\begin{tabular}{llcc}
\hline Species & Temp. $\left({ }^{\circ} \mathrm{C}\right)$ & Nitrate $(\mathrm{ppm})$ & Mean (range) survival (days) \\
\hline$X$. victoriensis & 15 & $<5$ & $69.6(57-92)$ \\
& 15 & 100 & $54.2(43-78)$ \\
& 20 & $<5$ & $47.9(22-94)$ \\
& 20 & 100 & $30.4(7-43)$ \\
C. aff. okadai & 15 & $<5$ & $57.4(5-106)$ \\
& 20 & $<5$ & $46.4(1-78)$ \\
\hline
\end{tabular}

cocoons had hatched: these cocoons remained attached to the exuviae but none subsequently hatched. When $X$. victoriensis worms were left on the host $(n=16)$ following deposition of the first cocoon, the mean number of cocoons laid over the 30day period was 5.7 (range 2-9), or one cocoon every 6.5 days, although cocoon deposition was irregular. Often, multiple cocoons were laid over a period of a few days, but then laying did not resume for up to 14 days.

Of the 20 crayfish experimentally infected with a single C. aff. okadai worm, significantly more $(80 \%)$ lost their branchiobdellidans within the first $48 \mathrm{~h}$ compared to $X$. victoriensis $\left(\chi^{2}=5.72, \mathrm{df}=1, P<0.05\right)$. Of the four remaining $C$. aff. okadai worms, three laid a cocoon (on days two, six and seven, respectively), while the remaining worm became detached after nine days. Of the three cocoons, two hatched (10 and 11 days later). All $X$. victoriensis and $C$. aff. okadai cocoons were laid on the ventral chelae or dorsal carapace, respectively, corresponding to the preferred host locations of the adult worms (James et al., 2015a).

\subsection{In vitro survival, reproduction, cannibalism and intraguild predation}

Under control conditions (nitrate $<5 \mathrm{ppm}$, temperature $15^{\circ} \mathrm{C}$ ) survival periods were up to 15 and 13 weeks for $C$. aff. okadai and $X$. victoriensis, respectively. There was no difference in the average survival time of $C$. aff. okadai and
$X$. victoriensis under low nitrate control conditions $\left(F_{1,77}=2.60, P=0.11\right)$, but both species survived significantly longer at $15^{\circ} \mathrm{C}$ than $20^{\circ} \mathrm{C}\left(F_{1,78}=14.48, P<0.0001\right.$; Fig. 2$)$. Under the high nitrate treatment, the mean survival of $X$. victoriensis was also significantly higher at $15^{\circ} \mathrm{C}$ than $20^{\circ} \mathrm{C}$ $\left(F_{1,77}=111.05, P<0.0001\right)$. For $X$. victoriensis, mean survival was significantly lower under conditions of high compared to low nitrate $\left(F_{1,77}=58.11, P<0.0001\right.$; Tab. 1$)$.

$X$. victoriensis did not lay cocoons in vitro, whereas 9 out of $20 \mathrm{C}$. aff. okadai worms maintained at $15^{\circ} \mathrm{C}$ and 4 out of 20 at $23{ }^{\circ} \mathrm{C}$ deposited globular cocoons, each containing a single embryo. These cocoons were not attached to the petri dish, but some were attached to each other via a peduncle (Fig. 3a). Most worms (76.9\%) deposited only a single cocoon, however, clusters of up to four were observed (Fig. 3b), and one worm laid six cocoons over 15 days. All cocoons were deposited within the first 23 days of the experiment. From a total of 19 cocoons, 47\% (9) hatched. All living juveniles were transferred individually to a new petri dish containing dechlorinated water: four survived over $48 \mathrm{~h}$ and, of these, two survived 23 days in vitro.

Both the size difference between the worms $\left(\chi^{2}=5.08\right.$, $\mathrm{df}=1, P=0.02)$ and treatment $\left(\chi^{2}=11.26, \mathrm{df}=4, P=0.02\right)$ had a significant effect on branchiobdellidan survival in cannibalism/intraguild predation experiments (Fig. 4). Among treatments, $X$. victoriensis/C. aff. okadai inter-specific pairs had significantly lower survival than all other treatments 


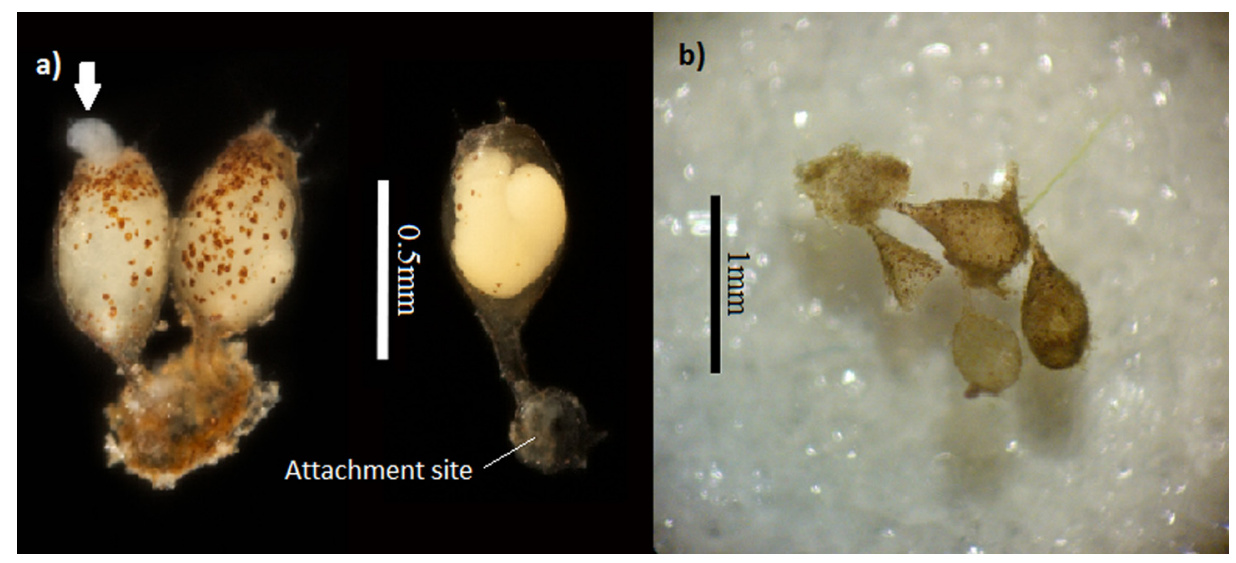

Fig. 3. (a) Transparent cocoons of Cambarincola aff. okadai containing larvae, juvenile worm (arrow head) emerging from the far left cocoon (image courtesy of Andy Mackie, National Museum Wales), and (b) empty cocoons.

$(P<0.001$ for all $)$ with $92 \%$ of $X$. victoriensis consumed within six weeks. Both intra-specific pairs had significantly higher survival than inter-specific pairs $(P<0.0001)$ and significantly lower survival than both controls (i.e. individual worms of either species) with $27 \%$ of smaller $X$. victoriensis and $33 \%$ of smaller $C$. aff. okadai consumed $(P<0.05)$. Intraspecific pairs of $X$. victoriensis and $C$. aff. okadai did not significantly differ from each other, and neither did $X$. victoriensis and $C$. aff. okadai individual worm controls.

\section{Discussion}

The populations of $C$. aff. okadai and $X$. victoriensis in south Wales have been present for at least four years (James et al., 2015a) suggesting that both species overcame any initial barriers associated with small founder population sizes. Whilst this may seem contradictory to the high initial decrease in $X$. victoriensis infrapopulations we observed in vivo, within 10 weeks these branchiobdellidans had established viable populations on all experimentally infected hosts. It is likely that the low initial survival of $X$. victoriensis on signal crayfish was a result of host grooming, which is known to be efficient in regulating branchiobdellidan numbers (Farrell et al., 2014). Once $X$. victoriensis began reproducing on the host, however, the rate of worm infrapopulation increase is likely to have outweighed the number removed through grooming. Establishment of worm infrapopulations and further invasion will be facilitated by this relatively fast reproductive rate, compared to some other freshwater annelids (Cook, 1969; Govedich et al., 2009). Furthermore, $X$. victoriensis laid cocoons (one every 6.5 days that hatched after 10-27 days) even when isolated on the host with no opportunity to mate, indicating the ability for internal sperm storage/self-fertilisation. Hermaphroditism and self-fertilisation are traits typically associated with successful invaders (Kennedy, 1994).

As observed in other branchiobdellidan species, we found that both $X$. victoriensis and $C$. aff. okadai were able to survive for extended periods off the host (Penn, 1959; Young, 1966; Creed et al., 2015). Furthermore, C. aff. okadai deposited cocoons off the host, only the second time this has been documented for branchiobdellidans (Woodhead, 1950). These characteristics will broaden the opportunity for worm transmission in the event of host moulting/death, potentially

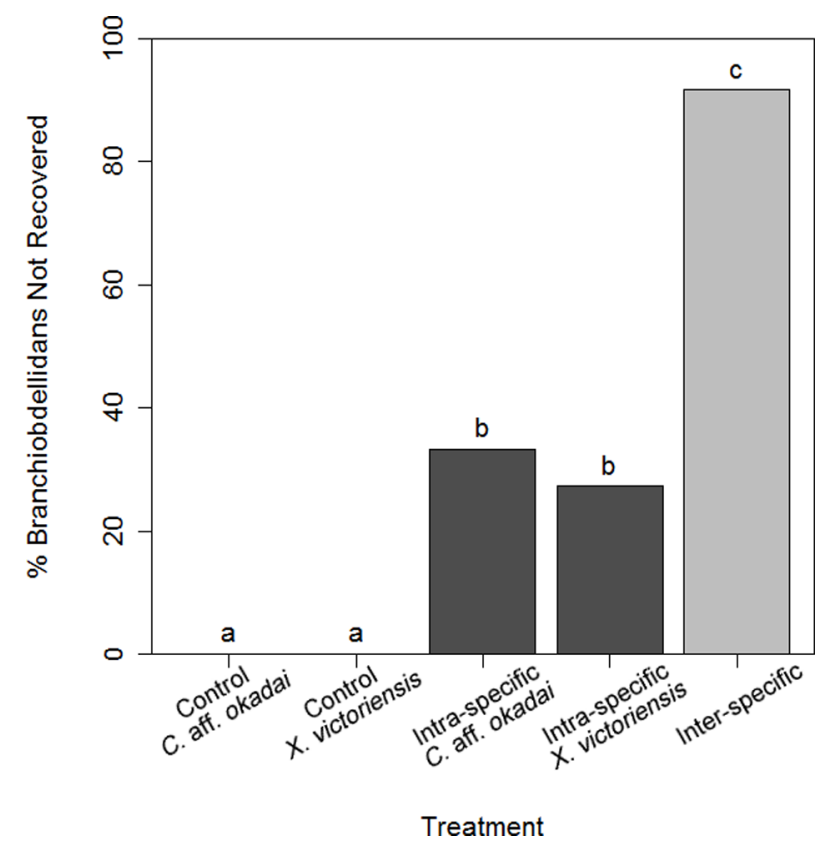

Fig. 4. Intraguild predation (proportion of branchiobdellidans not recovered) between Xironogiton victoriensis and Cambarincola aff. okadai (light grey bar) was higher than cannibalism (dark grey bars) when worms were maintained in vitro at $15 \pm 1{ }^{\circ} \mathrm{C}$ and $<10 \mathrm{ppm}$ nitrate. Letters show statistical differences; treatments that do not share letters are significantly different.

increasing the invasion success of these symbionts. However, no free-living worms were found in the invertebrate samples collected from the River Gavenny, suggesting that it is either not common for branchiobdellidans to leave the host in the wild or they are vulnerable to predation.

In terms of environmental tolerance, both $X$. victoriensis and $C$. aff. okadai were able to survive for extended periods at temperatures ranging from $15^{\circ} \mathrm{C}$ to $20^{\circ} \mathrm{C}$, and under nitrate concentrations of up to $100 \mathrm{ppm}$ (twice the legal limit for UK waters, according to the 1991 Nitrates Directive 91/676/EEC). Whilst this will increase the likelihood of these branchiobdellidans persisting/spreading in the UK, the survival of both species was reduced at higher temperatures and nitrate concentrations. Mean summer surface water temperatures 
(currently $22.2^{\circ} \mathrm{C}$ in the UK; Orr et al., 2010) are predicted to rise by up to $0.5^{\circ} \mathrm{C}$ per decade (Johnson et al., 2009), and nitrate levels as high as $100 \mathrm{ppm}$ have already been reported in British waters (Davies, 2013). Therefore, the persistence of both species of branchiobdellidans in the UK may be influenced by temperature fluctuations and/or pollution incidents.

Signal crayfish in the River Gavenny are commonly (75\%) co-infected with $X$. victoriensis and $C$. aff. okadai so the potential for intraguild predation is high. Indeed, we found that the larger $C$. aff. okadai regularly predated on $X$. victoriensis in vitro but not vice versa. Intraguild predation has previously been observed in congeneric branchiobdellidans, with $C$. vitreus being consumed by $C$. chirocephalus, which has a larger jaw size (Gale and Proctor, 2011). Intraguild predation is an important component of crayfish symbioses (Thomas et al., 2016), however to date the presence of $C$. aff. okadai has not prevented the establishment of $X$. victoriensis in the River Gavenny, most likely because they occupy separate host micro-habitats (James et al., 2015a). If niche overlap between these branchiobdellidans was forced, for example by removal of signal crayfish from the River Gavenny for control (reducing the number of available hosts), intraguild predation would likely become more important. Ultimately, this could impact the survival of competitively subordinate $X$. victoriensis, which are known to reduce the aggression and foraging success of infected crayfish (James et al., 2015b).

Overall, it is likely that both branchiobdellidan species will persist in the UK considering their relatively fast reproductive rate, direct life cycle and fairly broad environmental tolerance. Considering its ability to reproduce in vitro, $C$. aff. okadai, is likely a facultative symbiont, whereas $X$. victoriensis, considering its dependency on the host to reproduce and the detrimental effect it is known to have on host behaviour (James et al., 2015b), is an obligate symbiont that may be parasitic. Therefore, whilst both species have established in the UK and are predicted to spread with the dispersal of signal crayfish, $X$. victoriensis may have greater potential to influence ecosystem structure and function. The ability of $X$. victoriensis to persist/spread may, however, be influenced by the presence of competitively superior $C$. aff. okadai or other co-occurring symbionts. Overall, this study contributes towards understanding the symbiotic fauna of invasive non-native signal crayfish, and demonstrates the need to consider such cointroduced organisms as a "hidden cost" of biological invasion (Sherrard-Smith et al., 2014).

Conflicts of interest. The authors declare that they have no competing interests.

Acknowledgements. We thank Robby Mitchell, Graham Richardson and J. Rhidian Thomas for laboratory assistance, and Dr Andrew Mackie for providing images of Cambarincola aff. okadai cocoons. Morgan E. Williams Helminthology Scholarships funded KED and RH independently.

\section{Author's contributions}

JJ, KED and JC designed the study and drafted the manuscript. KED and RH conducted laboratory experiments. JJ and KED performed statistical analyses. All authors approved the final manuscript.

\section{References}

Cook DG. 1969. Observations on the life history and ecology of some Lumbriculidae (Annelida, Oligochaeta). Hydrobiologia 34: 561-574.

Creed RP, Lomonaco J, Thomas MJ, Meeks A, Brown BL. 2015. Reproductive dependence of a branchiobdellidan worm on its crayfish host: confirmation of a mutualism. Crustaceana 88: 385-396.

Davies G. 2013. Nitrates in water twice the legal level on South Downs. In: The Argus, 3 May 2013. Available from: http://www. theargus.co.uk (last consulted on: 2015/15/06).

DeWitt PD, Williams BW, Lu ZQ, Fard AN, Gelder SR. 2013. Effects of environmental and host physical characteristics on an aquatic symbiont. Limnologica 43: 151-156.

Didham RK, Tyliankis JM, Hutchinson MA, Ewers RM, Gemmell NJ. 2005. Are invasive species the drivers of ecological change? Trends Ecol Evol 20: 470-474.

Farrell KJ, Creed RP, Brown BL. 2014. Preventing overexploitation in a mutualism: partner regulation in the crayfish-branchiobdellid symbiosis. Oecologia 174: 501-510.

Gale KSP, Proctor HC. 2011. Diets of two congeneric species of crayfish worm (Annelida: Clitellata: Branchiobdellidae) from western Canada. Can J Zool 89: 289-296.

Gelder SR. 1999. Zoogeography of branchiobdellidans (Annelida) and temnocephalidans (Platyhelminthes) ectosymbiotic on freshwater crustaceans, and their reactions to one another in vitro. Hydrobiologia 406: 21-31.

Govedich FR, Bain BA, Moser WE, Gelder SR, Davies RW, Brinkhurst RO. Annelida (Clitellata): Oligochaeta, Branchiobdellida, Hirudinida, and Acanthobdellida. In: Thorp JH, Covich AP, eds. Ecology and classification of North American freshwater invertebrates, 3rd ed. London: Academic Press, 2009, pp. 385-410.

Graves S, Piepho H-P, Selzer L with help from Dorai-Raj S. 2015. multcompView: visualizations of paired comparisons. R package version 0.1-7. Available from: https://CRAN.R-project.org/pack age $=$ multcompView.

Gurevitch J, Padilla D. 2004. Are invasive species a major cause of extinctions? Trends Ecol Evol 19: 470-474.

Holdich DM, James J, Jackson C, Peay S. 2014. The North American signal crayfish with particular reference to its success as an invasive species in Great Britain. Ethol Ecol Evol 26: 232-262.

James J, Slater FM, Cable J. 2014. A.L.I.E.N. databases: addressing the lack in establishment of non-natives databases. Crustaceana 87: 1192-1199.

James J, Cable J, Richardson G, Davidson KE, Mackie ASY. 2015a. Two alien species of Branchiobdellida (Annelida) new to the British Isles: a morphological and molecular study. Aquat Invasions 10: 371-383.

James J, Davidson KE, Richardson G, Grimstead C, Cable J. 2015b. Reduced aggression and foraging efficiency of invasive signal crayfish (Pacifastacus leniusculus) infested with non-native branchiobdellidans (Annelida:Clitellata). Parasites Vectors 8: 596.

James J, Slater FM, Vaughan IP, Young KA, Cable J. 2015c. Comparing the ecological impacts of native and invasive crayfish: could native species translocation do more harm than good? Oecologia 178: 309-316.

Johnson AC, Acreman MC, Dunbar MJ, et al. 2009. The British river of the future: how climate change and human activity might affect two contrasting river ecosystems in England. Sci Total Environ 407: 4787-4798.

Kennedy CR. The ecology of introductions. In: Pike AW, Lewis JW, eds. Parasitic diseases of fish. UK: Samara Publishing Limited, 1994, pp. 189-208. 
Kouba A, Petrusek A, Kozak P. 2014. Continental-wide distribution of crayfish species in Europe: update and maps. Know Manag Aquat Ecosyst 413: 5.

Lockwood JL, Hoopes MF, Marchetti MP. 2013. Invasion ecology, 2nd ed. UK: Wiley-Blackwell, $456 \mathrm{p}$.

MacArthur RH, Wilson EO. 1967. The theory of island biogeography. Princeton, USA: Princeton University Press, $224 \mathrm{p}$.

MacLeod CJ, Paterson AM, Tompkins DM, Duncan RP. 2010. Parasites lost - do invaders miss the boat or drown on arrival? Ecol Lett 13: 516-527.

Niwa N, Archdale M, Matsuoka T, Kawamoto A, Nishiyama H. 2014. Microhabitat distribution and behaviour of Branchiobdellidan Holtodrilus truncatus found on the freshwater shrimp Neocaridina spp. from the Sugo River, Japan. Cent Eur J Biol 9: 80-85.

Orr HG, des Clers S, Simpson GL, et al. Changing water temperatures: a surface water archive for England and Wales. In: Kirby C, ed. Role of hydrology in managing consequences of a changing global environment. Newcastle, UK: British Hydrological Society, 2010, pp. 1-8.

Penn GH. 1959. Survival of branchiobdellid annelids without a crawfish host. Ecology 40: 514-515.

Prenter J, MacNeil C, Dick JTA, Dunn AM. 2004. Roles of parasites in animal invasions. Trends Ecol Evol 19: 385-390.

R Development Core Team. 2012. R: a language and environment for statistical computing. Vienna: R Foundation for Statistical Computing; 2009. http://www.R-project.org, ISBN 3-900051-07-0.

Rasband WS. 1997-2017. ImageJ. Bethesda, MD, USA: U.S. National Institutes of Health.
Sargent L, Baldridge A, Vega-Ross M, Towle K, Lodge D. 2014. A trematode parasite alters growth, feeding behavior, and demographic success of invasive rusty crayfish (Orconectes rusticus). Oecologia 175: 947-958.

Sherrard-Smith E, Chadwick EA, Cable J. 2014. The impact of introduced hosts on parasite transmission: opisthorchiid infections in American mink (Neovison vison). Biol Invasions 17: 115-122.

Skelton J, Farrell KJ, Creed RP, et al. 2013. Servants, scoundrels, and hitchhikers: current understanding of the complex interactions between crayfish and their ectosymbiotic worms (Branchiobdellida). Freshw Sci 32: 1345-1357.

Sol D, Maspons J, Vall-Ilosera M, et al. 2012. Unraveling the life history of successful invaders. Science 337: 580-583.

Souty-Grosset C, Holdich DM, Noel PY, Reynolds JD, Haffner P. 2006. Atlas of crayfish in Europe. Paris: Muséum National d'Histoire Naturelle, 187 p.

Taraschewski H. 2006. Host and parasites as aliens. J Helminthol 80: 99-128.

Thomas R, Vaughan I, Lello, J. 2013. Data analysis with R statistical software: a guidebook for scientists. Cardiff, UK: Eco-explore.

Thomas MJ, Creed RP, Skelton J, Brown BL. 2016. Ontogenetic shifts in a freshwater cleaning symbiosis: consequences for hosts and their symbionts. Ecology 97: 1507-1517.

Woodhead AE. 1950. Life history cycle of the giant kidney worm, Dioctophyma renale (Nematoda), of man and many other mammals. Trans Am Microsc Soc 69: 21-46.

Young W. 1966. Ecological studies of the Branchiobdellidae (Oligochaeta). Ecology 47: 571-578.

Cite this article as: James J, Davidson KE, Hunt R, Cable J. 2017. Assessing the invasion potential of non-native branchiobdellidans: experimental studies of survival, reproduction and competition. Knowl. Manag. Aquat. Ecosyst., 418, 35. 